\title{
Regression of Metastases after Nephrectomy for Renal Cell Carcinoma
}

\author{
SHERMAN JAY SILBER, CHENG-YANG CHANG and FRANK GOULD \\ Section of Urology, Department of Surgery, University of Michigan Medical Center, Ann Arbor, Michigan.
}

The rare observation that pulmonary metastases from renal cell carcinoma may regress after removal of the primary neoplasm has prompted many urologists to perform radical nephrectomy in apparently hopeless cases (Gonick and Jackiw, 1964; Garfield and Kennedy, 1972).

\section{Case Report}

E. C. (385-03-63-16), a 53-year-old man was admitted with a 1-year history of 30 pound weight loss, anorexia, and generalised weakness. He had one attack of gross, painless haematuria 3 months before admission. Physical examination revealed a large right flank mass. There were no palpable lymph nodes and no other masses. The haematocrit was $42 \%$, the White Blood Count 11,400; urinalysis showed no protein, sugar, WBCs or bacteria, but 7-8 RBCs per HPF. Chest X-ray revealed 5 metastases (Fig. 1).

Total serum protein was $6.3 \mathrm{gm} \%$ and albumin $2.1 \mathrm{gm} \%$. Alkaline phosphatase was 183 and $265 \mathrm{~m}$ units per ml (upper limit of normal $85 \mathrm{~m}$ units per $\mathrm{ml}$ ). The other liver functions were normal and there was no hypercalcaemia.

Intravenous urography revealed a large right renal mass and angiography demonstrated a large renal cell carcinoma replacing most of the right kidney. On abdominal exploration the tumour was found to be extensively invading perirenal tissue and many enlarged lymph nodes along the aorta and the common bile duct were biopsied. These nodes were not dissected but the kidney and Gerota's fascia were removed intact. Histologic examination of the tumour showed a poorly differentiated and spindle cell carcinoma interspersed with a few areas of the more classical clear cell variety (Fig. 2). The lymph nodes also showed metastatic renal cell carcinoma. The patient's post-operative recovery was unremarkable.

Chest X-ray 1 week after nephrectomy revealed no change. One month later only 2 of the metastases were still recognisable (Fig. 3). We had entertained the idea of starting him on Provera 1 month postoperatively but because of this spontaneous regression, he was not treated. Two months postoperatively only 1 metastasis was identifiable. This one was superimposed on the right hilum and did not change in size throughout this period, nor in the following 5 months (Fig. 4). In addition, the liver functions had all returned to normal and the patient was feeling strong and robust. By 1 year, however, the patient developed new pulmonary and bone metastases.

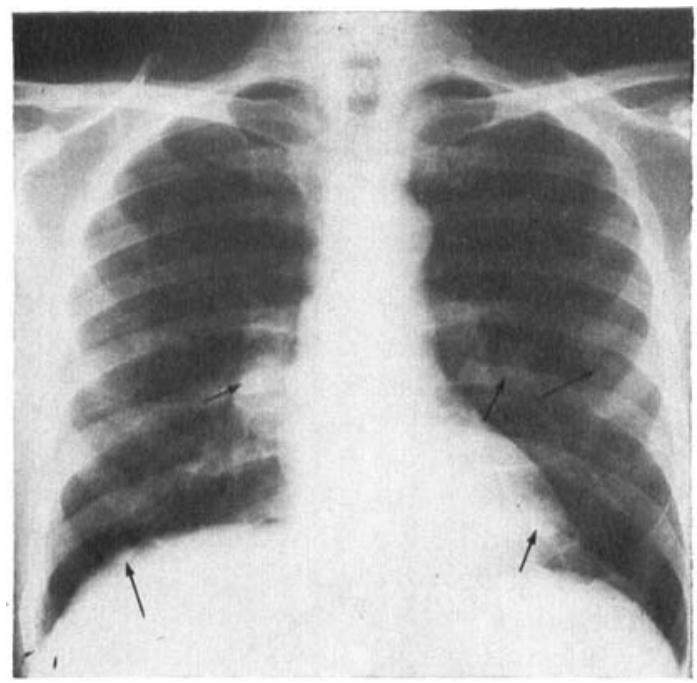

Fig. 1. Preoperative chest $X$-ray showing 5 metastases of varying size (arrows). 


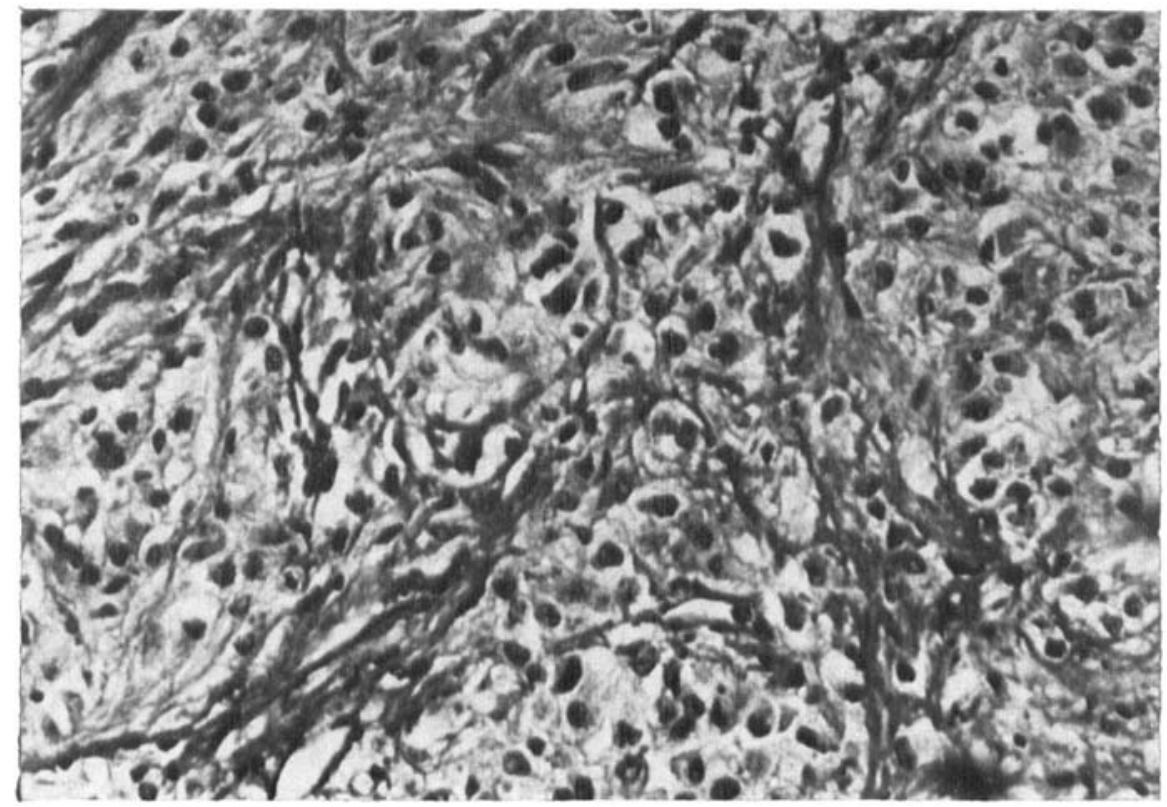

Fig. 2. Histologic section of tumour with poorly differentiated and clear cell carcinoma.

\section{Discussion}

There have been only 41 well-documented cases of regression of metastatic lesions from renal cell carcinoma unrelated to hormonal therapy or chemotherapy (Gonick and Jackiw, 1964; Adolfsson, 1966; Everson and Cole, 1966; Markewitz, Taylor and Veenema, 1967; Ridings, 1971; Garfield and Kennedy, 1972). 39 were pulmonary lesions, 30 followed nephrectomy, 2 followed radiation to the primary, 1 regressed spontaneously without nephrectomy and 6 were pulmonary metastases which occurred following nephrectomy and then spontaneously regressed. There has been a case of regression of a bone metastasis and intestinal metastasis (Mims et al., 1966). In 4 cases there was histological proof that the pulmonary coin lesions were indeed neoplasm (Ljungren et al., 1959; Gonick and Jackiw, 1964; Markewitz et al., 1967). In only 1 of these 4 cases however, did the regression of neoplasm directly follow nephrectomy (Markewitz et al., 1967). This patient died 1 year later of new metastases.

Regression is clearly not a common event. Middleton (1967) reported 33 patients with metastatic renal cell carcinoma who underwent nephrectomy without any regression of the metastatic lesions and no survivors after 2 years. The same author reports $45 \%$ and $34 \% 3$-year and 5-year survival for nephrectomy and resection of a solitary metastasis. Mims reported 97 patients with metastatic renal cell carcinoma treated by nephrectomy with only 1 case of spontaneous regression of multiple bone metastases (Mims et al., 1966). Their overall 5-year survival rate was $14.6 \%$. Their 1 patient with regression of bone metastases after nephrectomy had a profound lymphocytic reaction surrounding the primary and the authors suggest an immunologic explanation for the regression.

In all the reported cases, regression of metastases was noted by 4 months to 1 year after nephrectomy and could recur in the same or other areas at a later date. Regression was palliative and did not necessarily mean that the patient was cured.

There is a great deal of speculation about the cause of these regressions. By reducing the large amount of tumour antigen in the primary, the host's own immune defences might be able to overcome the remaining tumour. Alternatively, removing the primary might also remove hormonal 

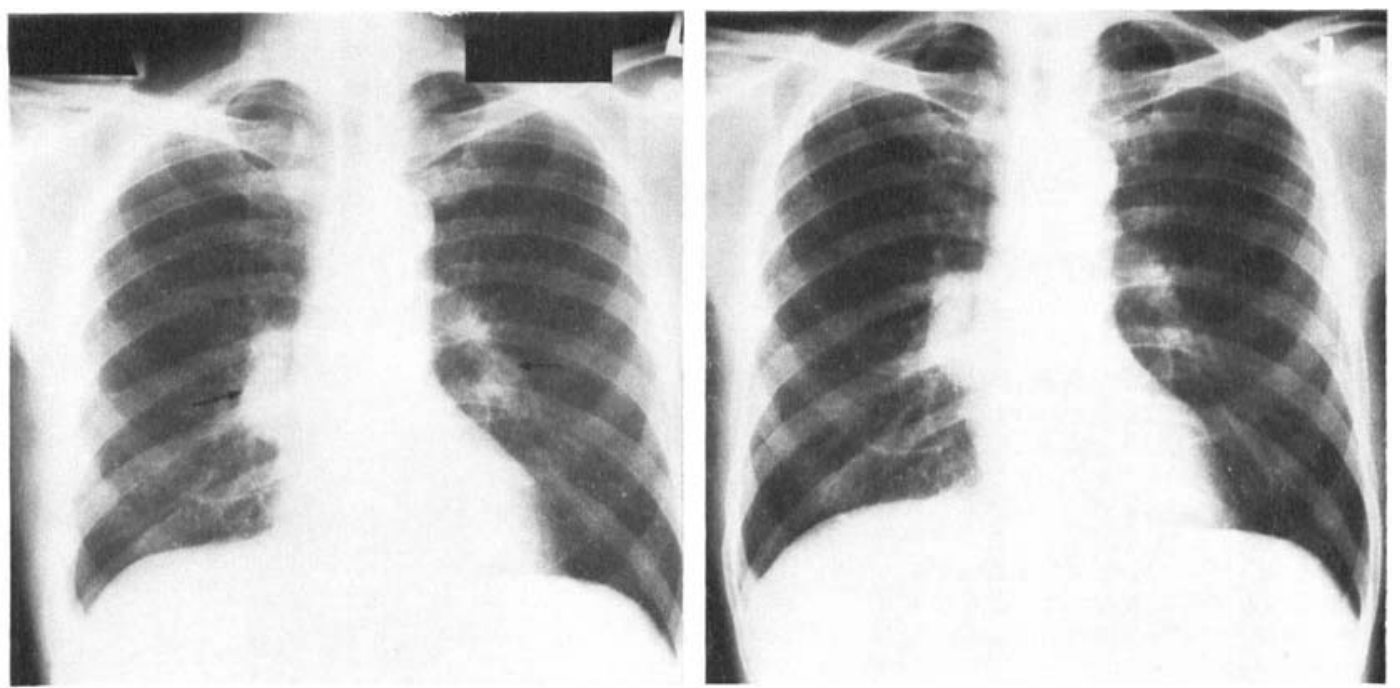

Fig. 3. Chest X-ray 1 month after nephrectomy showing only 2 of the original metastases (arrows).

Fig. 4. Chest X-ray 2 months after nephrectomy showing only the 1 metastasis superimposed on the right hilum. This has not changed in size since the preoperative film.

or other carcinogenic substances released by the primary. A third possibility is that regression is an unpredictable spontaneous event unrelated except by random chance to the nephrectomy.

Studying these rare patients may eventually help us to understand that peculiar balance that exists between the host and his renal cell carcinoma.

\section{Summary}

A case of an extensive renal cell carcinoma with temporary regression of pulmonary metastases is reported.

The literature of similar reported cases is briefly reviewed.

\section{References}

Adolfsson, G. (1966). Regression of hypernephroma. Urologia Internationalis, 21, 365-374.

EVERson, T. C. and Cole, W. H. (1966). In: Spontaneous Regression of Cancer, Philadelphia: Saunders, pp. 11-87.

GARFIELD, D. H. and KENNEDY, B. J. (1972). Regression of metastatic renal cell carcinoma following nephrectomy. Cancer, 30, 190-196.

GonICK, P. and JACKIW, N. M. (1964). Regression of pulmonary metastases from renal adenocarcinoma. Journal of Urology, 92, 270-274.

Ljunggren, E., Holm, S., Karth, B. and Pompeius, R. (1959). Some aspects of renal tumors with special reference to spontaneous regression. Journal of Urology, 82, 553-557.

Markewitz, M., TAYLOR, D. A. and Veenema, R. J. (1967). Spontaneous regression of pulmonary metastases following palliative nephrectomy. Cancer, 20, 1147-1154.

Middleton, R. G. (1967). Surgery for metastatic renal cell carcinoma. Journal of Urology, 97, 973-977.

Mims, M. M., Christenson, B., Schlumberger, F. C. and Goodwin, W. E. (1966). A 10-year evaluation of nephrectomy for extensive renal-cell carcinoma. Journal of Urology, 95, 10-15.

RIDINGS, G. R. (1971). Renal adenocarcinoma: regression of pulmonary metastases following irradiation of primary tumour. Cancer, 27, 936-938.

\section{The Authors}

Sherman Jay Silber, MD, Resident (now chief, Urology Section, Veterans Administration Hospital, San Francisco).

Cheng-yang Chang, MD, Assistant Professor of Urology.

Frank Gould, MD, Resident. 